\title{
Integración del conocimiento científico y de la capacidad argumentativa en tomas de decisión sobre temas sociocientíficos
}

\author{
Araitz Uskola iD \\ Departamento de Didáctica de la Matemática y de las Ciencias Experimentales, Facultad de Educación de \\ Bilbao, Universidad del País. Leioa. araitr.uskola@ebu.eus \\ Begoña Burgoa \\ Instituto de Evaluación e Investigación Educativa ISEI-IVEI (Gobierno Vasco), LIEC (Universitat \\ Autònoma de Barcelona).bbetxaburu@gmail.com
}

Gurutze Maguregi

Departamento de Didáctica de la Matemática y de las Ciencias Experimentales, Facultad de Educación de Bilbao, Universidad del País.Leioa. gurutze.maguregi@ehu.eus

[Recibido: 6 noviembre 2019. Revisado: 1 abril 2020. Aceptado: 14 septiembre 2020]

Resumen: Esta investigación aborda la integración de las capacidades de argumentación y explicación de fenómenos científicos, en tomas de decisión sobre vacunación. Se ha diseñado un método de análisis adaptando herramientas de la literatura. Se han analizado las producciones escritas y discusiones de 72 estudiantes del Grado de Educación Primaria que han participado en las actividades diseñadas. Se observa que han desarrollado varios aspectos de la competencia argumentativa, y que quienes han expresado un modelo de sistema inmunológico de mayor complejidad argumentan mejor. Sin embargo, menos del 30\% se han referido al modelo en sus argumentos, llegando a un $15 \%$ en la toma de decisión de repercusión colectiva. Se concluye que la integración entre las capacidades es mejorable y que implica la necesidad de analizar qué dificulta la utilización del conocimiento científico en las tomas de decisión.

Palabras clave: Argumentación; Controversias sociocientíficas; Formación inicial de Profesorado; Modelización; Sistema inmunológico.

Integration of the scientific knowledge and the argumentation competence in decisions about socioscientific issues

\begin{abstract}
This research focuses on the integration among the skills of argumentation and the explanation of scientific phenomena, during decision making about vaccination. An analysis method has been developed adapting tools from the literature. The written productions and oral discussions made by 72 Elementary Preservice Teachers who took part in the activities have been analyzed. It can be observed that they have improved their competence for argumentation in several ways, and that those who expressed a more complex immune system model argue better. However, less than 30\% have referred to the model in their arguments, 15\% in the case of social repercussion decision making. It is concluded that the integration between the skills is improvable and that it is necessary to analyze what makes it difficult to use the scientific knowledge in the socioscientific decision makings.
\end{abstract}

Keywords: Argumentation; Immune system; Modeling; Socio-scientific issues; Teachers' initial training.

Para citar este artículo: Uskola A., Burgoa B. y Maguregi G. (2021) Integración del conocimiento científico en la argumentación sobre temas científicos. Revista Eureka sobre Enseñanza y Divulgación de las Ciencias 18(1), 1101.doi: 10.25267/Rev_Eureka_ensen_divulg_cienc.2021.v18.11.1101

\section{Introducción}

Tanto la comunidad científica como expertos en educación científica (COSCE 2011; Hodson 1992; Millar y Osborne 1998) señalan la necesidad de potenciar una renovación de la enseñanza de las ciencias, y promulgan que el conocimiento científico no debe ser entendido 
como una acumulación de datos sobre el mundo, sino como un conocimiento competencial, donde el conocimiento científico se transfiera a una situación distinta de aquella en la que fue aprendido. En el currículo básico de Educación primaria en España (Ministerio de Educación, Cultura y Deporte (2014), p. 17) se señala que "El trabajo en el área de las Ciencias de la Naturaleza pretende desarrollar una actitud de toma de conciencia, participación y toma de decisiones argumentadas ante los grandes problemas a los que nos enfrentamos en la actualidad, ayudándonos a valorar las consecuencias." Para que esto pueda producirse, es necesario desarrollar la competencia científica del alumnado (OECD 2016). Pedrinaci, Caamaño, Cañal y de Pro (2013) observaron las carencias de la definición de competencia científica en el currículo español, en el que se la limita a una habilidad y hay componentes importantes en otras definiciones que se obvian. Ellos argumentaron que en el aula deben abordarse varias capacidades relacionadas con el conocimiento, la práctica y la naturaleza de la ciencia. En cuanto a las relacionadas con la práctica de la ciencia, se pueden agrupar en argumentar, modelizar e indagar (OECD 2016). En algunas ocasiones, a efectos prácticos, se desarrolla o evalúa específicamente alguna de estas capacidades, pero están estrechamente interrelacionadas (Jiménez-Aleixandre, Bravo y Puig 2009) y es de alto interés estudiar cómo se desarrollan en interrelación (Böttcher y Meisert 2010; Mendonça y Justi 2013).

Diversos estudios han puesto de manifiesto la relación entre la argumentación y la modelización, sin embargo, hay pocos trabajos que analicen ambas prácticas (Blanco 2015). Los resultados de una investigación previa (Uskola, Burgoa y Maguregi 2018) señalaban que los estudiantes habían construido un modelo de Sistema Inmunológico (SI) acorde con el modelo de ser vivo (92-96\% en las situaciones de transferencia cercana, 44\% en la situación de transferencia lejana). El presente estudio aborda la argumentación de los y las estudiantes en tomas de decisión relacionadas con el modelo de SI, y cómo incorporan dicho modelo a sus argumentos. La construcción de un modelo de SI acorde al conocimiento actual, y su utilización en la toma de decisiones, como por ejemplo en torno a la vacunación, podría acercar al alumnado hacia una visión de la ciencia cercana y útil para la resolución de problemas de carácter social, al tratarse de un modelo que está adquiriendo más relevancia en la actualidad.

\section{Marco teórico}

\section{Controversias sociocientíficas}

Las cuestiones sociocientíficas están basadas en aspectos científicos; pero son objeto de debate en la sociedad, al implicar también, entre otros, aspectos políticos, éticos, ambientales o económicos (Jiménez-Aleixandre 2010; Sadler y Zeidler 2005). Al tratarse de cuestiones complejas que pueden movilizar una diversidad de conocimientos, valores y capacidades, se utilizan en las clases de ciencias con diferentes fines (Sadler y Zeidler 2005; Simonneaux 2008). Así, se consideran adecuadas para el aprendizaje de conceptos científicos, ya que el estudiante sitúa el contenido en un contexto más amplio que le dota de significado (Sadler 2011). Kuhn (1993) propuso utilizar temas sociocientíficos, reconociendo que se puede dar la paradoja de que en éstos pueda desarrollarse el pensamiento científico mejor incluso que en los científicos, ya que en estos últimos, los estudiantes pueden sentirse inhibidos por una fuerte creencia en su ignorancia. La utilización de controversias sociocientíficas en el aula no solo pretende favorecer la construcción de conocimiento científico, sino también el conocimiento acerca de la propia naturaleza de la ciencia, el fomento de actitudes positivas hacia la ciencia y hacia el medio (Sadler 2011), así como el pensamiento crítico, la capacidad de argumentación y de toma de decisiones (Kortland 1996; Sadler 2011; Simonneaux 2008). 
El interés por la incorporación de las cuestiones sociocientíficas en las clases de ciencias también se ha reflejado en el contexto español (p. e. Bravo 2012; Díaz y Jiménez-Liso 2012; García-Milá, Gilabert, Erduran y Felton 2013; Jiménez-Aleixandre 2010; Solbes 2013).

Respecto a cómo se desarrolla el proceso de argumentación en estos contextos, numerosos estudios han abordado la cuestión. Los resultados en el caso del desarrollo de la capacidad de argumentación indican que mejora la capacidad de justificar y refutar (Bravo 2012; García-Milá et al. 2013), por lo que se consideran contextos adecuados (Jiménez-Aleixandre 2010). Los resultados en el caso de la utilización del conocimiento científico indican que en temas sociocientíficos prevalecen otros tipo de consideraciones (Nielsen 2012; Ratcliffe 1997), y que incluso cuando los y las estudiantes apelan al conocimiento científico lo hacen con un fin pragmático para ganar la discusión y no debería considerarse que lo hagan como prueba (Nielsen 2012).

En lo relativo al tema de este trabajo, la vacunación puede considerarse una cuestión sociocientífica, ya que la decisión que se tome frente a ella no se basa sólo en hechos científicos, sino que también se barajan valores y creencias personales y de influencia social. Díaz y Jiménez-Liso (2012) hallaron que, entre todas temáticas de las cuestiones sociocientíficas, las relacionadas con la salud ocupaban el tercer puesto en las propuestas llevadas al aula, mientras que eran las que más frecuentemente aparecían en las noticias de prensa. El trabajo de Lundström, Ekborg e Ideland (2012), realizado con siete estudiantes de educación secundaria, versó sobre vacunación. Investigaron qué justificaciones manejaban en la toma de decisión sobre la vacunación frente a la gripe y si utilizaban el conocimiento científico como base. Las respuestas se categorizaron en riesgos, solidaridad y conocimiento, e incluyeron también las menciones a los agentes que influían en su decisión: familiares y amigos, escuela, medios de comunicación y sociedad. Sólo una estudiante utilizó su conocimiento científico como base para su decisión. Los autores concluyeron que existe dificultad en utilizar conocimientos científicos en distintos contextos y que esto constituye un problema para la educación científica.

\section{Argumentación y modelización}

\section{Argumentación}

Hoy día la dimensión argumentativa ha adquirido gran importancia en el aprendizaje de las ciencias porque contribuye al desarrollo de: a) la competencia para aprender a aprender, b) el pensamiento crítico, fomentando con ello la capacidad de participación en decisiones sociales; c) competencias relacionadas con la forma de trabajar de la comunidad científica, así como al desarrollo de ideas sobre la naturaleza de la ciencia que hagan justicia a su complejidad (Jiménez-Aleixandre 2011).

La capacidad de argumentar puede ser analizada en función del contexto en que se realiza y está determinada en todos los casos por la capacidad de basar las conclusiones en justificaciones y datos. Es decir, la referencia a datos y justificaciones (Jiménez-Aleixandre 2010) es un indicador de calidad. Sin embargo, en el caso de las controversias sociocientíficas en las que se demanda una posición o una toma de decisión justificada, el tener en cuenta las limitaciones de la propia decisión y las ventajas de la posición contraria supone también la demostración de un nivel alto en la capacidad argumentativa (Kortland 1996); pero es la construcción de refutaciones a las justificaciones o datos del argumento contrario el elemento que determina un mayor nivel de calidad argumentativa (Erduran, Simon y Osborne 2004; Simmonneaux 2008). De manera coherente con esta perspectiva, Osborne et al. (2016) establecieron tres niveles para su progresión de aprendizaje sobre argumentación. En su propuesta, el paso de un nivel a otro venía dado por el grado de coordinación entre elementos 
del argumento. Además diferenciaron los niveles para el caso de construir un argumento propio y para el caso de criticar el de otra persona, hallando que los estudiantes tienen especiales dificultades en esto último. Tener en cuenta el punto de vista contrario y refutarlo son, pues claves a la hora de determinar la calidad de la argumentación. Entre las investigaciones sobre la calidad de la argumentación que establecen como criterios la justificación de la posición, la toma de perspectiva múltiple y las refutaciones, destacan las de Sadler y Donnelly (2006), que los utilizaron para evaluar los argumentos elaborados por estudiantes al ser entrevistados, y las de Felton, García-Milá y Gilabert (2009).

Así, se consideran indicadores de una alta calidad en la argumentación las desventajas o limitaciones de la propia opción o a las ventajas de la contraria cuando se trata de controversias sociocientíficas (Felton et al. 2009; Kortland 1996). No obstante, el nivel más alto se corresponde con la formulación de refutaciones (Erduran, Simon y Osborne 2004).

Felton et al. (2009) observaron que los argumentos escritos por los y las estudiantes de secundaria posteriormente a una discusión en parejas, eran de mayor calidad que los escritos anteriormente y que mejoraban especialmente a la hora de justificar la opción escogida y de reconocer las limitaciones de la propia opción. Analizando la estructura de los argumentos, incluyeron los aspectos relacionados con las limitaciones de la propia opción o las ventajas de las demás en las refutaciones (García-Milá, Gilabert, Erduran y Felton 2013).

\section{Integración de la modelización y la argumentación}

El conocimiento científico busca la explicación de los fenómenos y su predicción mediante la construcción y utilización de modelos científicos (Schwarz et al. 2009). Hay diferentes definiciones de modelo (Oliva 2019), siendo una de las más utilizadas la de representación abstracta, estructurada y simplificada de una idea, objeto, proceso o sistema, que incluye elementos simbólicos de sus características principales y que trata de explicar y predecir fenómenos científicos (Gilbert, Boulter y Elmer 2000). La enseñanza de las ciencias basada en modelos implica el uso de varias situaciones en las que el alumnado, al igual que la comunidad científica, practica la modelización, que incluye actividades de expresión, de construcción, de aplicación y de revisión de modelos (Marchán-Carvajal y Sanmartí 2015; Mendonça y Justi 2014). Esto es, el alumnado escoge y justifica un modelo para representar el fenómeno; propone modelos intermedios y los comunica para que sean evaluados y modificados si es el caso, etc. Así, la argumentación es un proceso de evaluación crítica de los modelos en el sentido de la idoneidad de uno o varios modelos rivales en función de su coherencia lógica y los datos empíricos disponibles. Así, el modelo más apropiado es el que logra sobrevivir a la refutación debido a sus justificaciones (Cardoso y Justi 2014). Por ello, la argumentación es inherente a la producción de modelos (Böttcher y Meisert 2010).

A pesar de la relación entre la argumentación y la modelización, apenas hay estudios que investiguen ambas prácticas (Blanco 2015), y el abordaje de la problemática ha sido variado. Así, se ha analizado qué oportunidades para argumentar se presentan en las diferentes fases de la modelización (Mendonça y Justi 2013; Passmore y Svoboda 2011) concluyendo que el acto de modelizar en ciencias es un acto argumentativo, aunque dicha argumentación adquiera objetivos diferentes (Berland y Reiser 2009) según la fase de modelización de la que se trate. La argumentación se produce durante las etapas que dan nombre a la construcción, uso, evaluación y revisión de los modelos, cuando las y los estudiantes están participando en: (i) la interpretación de los fenómenos, cuando definen el alcance del fenómeno que está siendo modelado; (ii) la búsqueda de evidencias; (iii) el establecimiento de relaciones entre los datos y el modelo; y (iv) la evaluación del modelo (Passmore y Svoboda 2011). 
La articulación entre el conocimiento científico y la argumentación ha sido objeto de varias investigaciones. Se ha hallado que es necesario un conocimiento conceptual mínimo para poder elaborar argumentos (Sadler y Donnelly 2006; Sadler y Fowler 2006) y para que argumentar pueda facilitar la profundización en el conocimiento (von Aufschnaiter, Erduran, Osborne y Simon 2008). Sadler y sus colegas proponen un Modelo de Umbral según el que hay, por lo menos, dos umbrales de nivel de conocimiento conceptual, de tal manera que un aumento de nivel conceptual entre dos umbrales no llevaría aparejada una mejora en la calidad argumentativa, que sólo mejoraría cuando se traspasa el umbral. Baytelman, Iordanou y Constantinou (2020) investigaron la relación entre creencias epistémicas, conocimiento científico previo y los argumentos que esgrimían 243 profesores en formación inicial al presentarles tres escenarios de dilemas sociocientíficos, uno de ellos relacionado con la vacunación. Hallaron que los estudiantes con mayor conocimiento previo, formulaban más argumentos y de mejor calidad. En España hay varios estudios que han analizado la integración de la construcción de modelos y de la argumentación, por ejemplo, el de Blanco (2015) con estudiantes de secundaria y bachillerato, el de Blanco Anaya, Díaz de Bustamante y Mendonça (2019), con estudiantes de bachillerato, ambos en contextos científicos de geología, o el de Puig, Ageitos y Jiménez-Aleixandre (2017), con estudiantes de secundaria, en un contexto científico sobre genética. Blanco Anaya et al. (2019) analizaron a estudiantes de bachillerato que construían un modelo sobre la historia geológica de un sinclinal, viendo que la contraargumentación y especialmente la refutación jugaban un papel importante en la evolución de los modelos.

\section{Objetivos}

Teniendo en cuenta la importancia de la argumentación en la toma de decisiones sobre temas sociocientíficos y que dichas argumentaciones deberían apelar al conocimiento conceptual, es decir, al modelo científico sobre el tópico, en este trabajo se analiza en qué medida la toma de decisión sobre aspectos relacionados con la salud está basada o tiene relación con el modelo construido sobre el Sistema Inmunológico (SI). En este sentido, las preguntas de la investigación son:

1- ¿Qué aspectos de la argumentación se desarrollan en las tomas de decisión (TD) de tipo personal (TD Personal) y social (TD Social) sobre controversias sociocientíficas relacionadas con el funcionamiento del Sistema Inmunológico (SI)?

2- ¿Qué relación se establece entre el modelo construido sobre Sistema Inmunológico (SI) y la calidad de la argumentación?

\section{Metodología}

\section{Participantes}

La investigación se realizó con alumnado del Grado de Educación Primaria durante el primer semestre del curso 2016/17. Los participantes fueron estudiantes de $4^{\circ}$ curso del Grado de Educación Primaria que cursaban las asignaturas «Nuevas Tendencias en la Didáctica de las ciencias» y «Actividades, instrumentos y recursos en la enseñanza de las ciencias». En las actividades grupales, se formaron 18 grupos de trabajo, de 4-5 miembros. Para este estudio, se han tenido en cuenta los datos de los 72 estudiantes (22,3 años de media, 62,5\% chicas) que participaron en todas las actividades analizadas. En cuanto a la discusión final, se formaron grupos distintos a los de trabajo, concretamente 23 grupos de 3-4 estudiantes, de los que fueron grabados en audio 18 escogidos al azar (61 estudiantes), debido a la baja disponibilidad de grabadoras. Se comprobó que el promedio del desempeño en los distintos aspectos de la argumentación de los 61 estudiantes grabados fue equivalente al promedio de los 72. Los 
nombres de los y las estudiantes se han sustituido por pseudónimos con la forma An o On, A si son chicas u $\mathrm{O}$ en el caso de que sean chicos y n el número del estudiante.

\section{Secuencia de actividades}

El equipo formado por las tres autoras diseñó una secuencia de actividades en torno a la vacunación, que fue implementada por dos de ellas. Se dedicaron un total de 9 horas de clase a las actividades, distribuidas en seis sesiones a lo largo de 8 semanas. La secuencia de actividades se ajusta a las cuatro fases del ciclo de aprendizaje de Jorba y Sanmartí (1996), y se detalla en la tabla 1.

La Fase 1, que se corresponde con la Exploración (Jorba y Sanmartí 1996), buscaba que el alumnado explicitara individualmente sus conocimientos sobre el sistema inmunitario y la vacunación, mediante las preguntas ¿Por qué no se pasa la varicela más de una vez?., Explica qué pasa en tu cuerpo cuando se infecta una herida y ¿Qué ocurre en tu cuerpo cuando te vacunas? También se les preguntó sobre su postura frente a la vacunación (TD Personal) y frente a su obligatoriedad (TD Social). Se formaron grupos de trabajo que formularon las preguntas que les había suscitado la realización de las actividades.

Durante la Fase 2, en la que se da la Introducción del conocimiento (Jorba y Sanmartí 1996), se pusieron en común las preguntas formuladas. Las profesoras ayudaron a ordenar dichas preguntas según hacían referencia a: procesos; elementos estructurales (partes del cuerpo) que intervienen en dichos procesos; cambios en el propio sistema; desventajas de la vacunación; otros. Cada grupo tenía que buscar información sobre todos los temas anteriores, para lo que distribuyeron tareas entre sus miembros y realizaron una puesta en común posterior, en clase.

A continuación, en la Fase 3, de Estructuración (Jorba y Sanmartí 1996), con la ayuda de las profesoras, los y las estudiantes identificaron los principales elementos y procesos implicados en el modelo de SI. Seguidamente, propusieron situaciones o fenómenos en los que se podía aplicar el modelo. Las situaciones que plantearon estaban relacionadas con enfermedades infecciosas, heridas infectadas, vacunación y alergias. Cada grupo seleccionó una de ellas para construir una maqueta tridimensional explicativa.

La Fase 4, de Aplicación (Jorba y Sanmartí 1996) o Transferencia (Garrido 2016), se planteó desde dos vertientes:

a) Se crearon actividades en las que se buscaba la aplicación del conocimiento construido (SI) en situaciones cercanas a los contextos trabajados (transferencia cercana) (Explica el funcionamiento de las vacunas, Explica cómo trabaja el sistema inmunológico), así como la transferencia lejana en una situación distinta ( $2 Q u e ́$ ocurre en tu cuerpo cuando te tatúas?).

b) Se plantearon situaciones en las que se les solicitaba tomar decisiones justificadas. En el caso de la TD Personal, se explicaban los problemas asociados al virus del papiloma humano y se preguntaba al alumnado si pondrían o no la vacuna a su hija. En el caso de la TD Social, sobre la obligatoriedad de la vacuna contra la difteria, se planteó una discusión grupal, que duró 6-28 minutos y seguidamente tomaron una decisión argumentada individual por escrito. 
Tabla 1. Secuencia de actividades.

\begin{tabular}{|c|c|c|c|}
\hline Fase 1 & Fase 2 & Fase 3 & Fase 4 \\
\hline $\begin{array}{l}\text { Explicitación de } \\
\text { conocimiento/ideas sobre } \\
\text { el SI y su funcionamiento } \\
\text { (semana 1) }\end{array}$ & $\begin{array}{l}\text { Redefinición de preguntas } \\
\text { (semana 1) }\end{array}$ & $\begin{array}{l}\text { Construcción de maquetas } \\
\text { sobre una situación } \\
\text { relacionada con el } \\
\text { funcionamiento del SI } \\
\text { (semana 5) }\end{array}$ & $\begin{array}{l}\text { Discusión y } \\
\text { argumentación en TD } \\
\text { Social (semana 6) }\end{array}$ \\
\hline $\begin{array}{l}\text { Argumentación en TD } \\
\text { Personal (semana 1) } \\
\text { Argumentación en TD } \\
\text { Social (semana 1) }\end{array}$ & $\begin{array}{l}\text { Búsqueda e intercambio } \\
\text { de información (semana 3) }\end{array}$ & $\begin{array}{l}\text { Generalización del modelo } \\
\text { (semana 5) }\end{array}$ & $\begin{array}{l}\text { Argumentación en TD } \\
\text { Personal (semana 8) } \\
\text { Aplicación del modelo en } \\
\text { preguntas conceptuales } \\
\text { (semana 8) }\end{array}$ \\
\hline $\begin{array}{l}\text { Formulación de preguntas } \\
\text { (semana 1) }\end{array}$ & & & \\
\hline
\end{tabular}

\section{Instrumentos y métodos de análisis}

En este estudio se siguió una metodología de carácter interpretativo (Erickson 1989) para dar respuesta a las preguntas de investigación. Para dar fiabilidad al análisis (Gee 1999), las 144 respuestas de la actividad individual final y las 18 discusiones grupales fueron analizadas por las tres investigadoras, llegando a un grado de consenso del $87 \%$ en el conjunto de criterios. Tras discutir y consensuar los disensos, cada una de las 144 respuestas de la actividad individual inicial fueron evaluadas por dos de las autoras, con un grado de acuerdo del $95 \%$. Los desacuerdos fueron discutidos, llegando a acuerdos en todos los casos.

Para este estudio, se tuvieron en cuenta las respuestas escritas en las TD Personal y Social de la Fase 1 y de la Fase 4, así como las discusiones grupales previas a la TD Social de la Fase 4. En los casos en que se determinó si había diferencias estadísticamente significativas entre las Fases, se calcularon los tamaños de efecto (d de Cohen). Para ello, en primer lugar, se determinó si se podía eliminar la hipótesis nula (no hay efecto) utilizando el test no paramétrico de Wilcoxon para variables de escala, para lo que se utilizó el software SPSS. A continuación, se calculó la d de Cohen como la diferencia de los promedios dividido entre la desviación estándard en el cuestionario final. Hay que tener en cuenta que suele considerarse que un valor de d mayor a 0,5 está asociado a un tamaño de efecto moderado, y uno de 0,8 o mayor, a un efecto grande (Morales 2011).

\section{Calidad de la argumentación}

En este trabajo se ha evaluado la calidad de los argumentos en base a tres criterios (Justificación, Desventajas y Posición contraria), basados en la literatura experta, adaptando para ello la propuesta de Sadler y Donnelly (2006) para entrevistas. Se establecieron niveles para cada criterio, de tal forma que el nivel más alto en el caso de los criterios Desventajas y Posición contraria se correspondía a la formulación de refutaciones (Erduran, Simon y Osborne 2004). En la tabla 2 se muestran los criterios y niveles, así como ejemplos de todos los niveles. 
Tabla 2. Criterios para evaluar la calidad de la argumentación.

\begin{tabular}{|c|c|c|c|}
\hline Criterios & Niveles & Descripción & Ejemplo \\
\hline \multirow{3}{*}{ Justificación } & 2 & $\begin{array}{l}\text { Da más de un dato y/o } \\
\text { justificación }\end{array}$ & $\begin{array}{l}\text { A13 (TD Social, A Favor): La difteria puede llevar a morir a } \\
\text { un niño [Salud Individual] y además como es contagiosa } \\
\text { puede transmitir a los demás el peligro que tiene ese niño } \\
\text { [Salud Pública]. }\end{array}$ \\
\hline & 1 & $\begin{array}{l}\text { Da un dato o una } \\
\text { justificación }\end{array}$ & $\begin{array}{l}\text { A28 (TD Personal, A Favor): Le pondría la vacuna. De este } \\
\text { modo su cuerpo creará anticuerpos contra el virus, así que } \\
\text { de estar en contacto con el virus su cuerpo estará preparado } \\
\text { para hacerle frente [Salud Individual]. }\end{array}$ \\
\hline & 0 & $\begin{array}{l}\text { No hay datos ni } \\
\text { justificaciones }\end{array}$ & $\begin{array}{l}\text { A37 (TD Social, A Favor): En nuestro grupo hemos llegado } \\
\text { a un acuerdo, que la vacuna sea obligatoria. De todas } \\
\text { formas, pensamos que si es obligatoria debe ser gratuita. }\end{array}$ \\
\hline \multirow{3}{*}{ Desventajas } & 2 & $\begin{array}{l}\text { Hace referencia a } \\
\text { alguna desventaja y la } \\
\text { refuta }\end{array}$ & $\begin{array}{l}\text { A1 (TD Social, A Favor): En algunos casos la efectividad de } \\
\text { la vacuna es limitada [Desventaja] pero como en los niños } \\
\text { pequeños se crean células inmunitarias más rápido, es más } \\
\text { probable que en su caso la respuesta sea más eficaz y rápida } \\
\text { [Refutación]. }\end{array}$ \\
\hline & 1 & $\begin{array}{l}\text { Hace referencia a } \\
\text { alguna desventaja } \\
\text { (dato/justificación) de } \\
\text { la postura defendida }\end{array}$ & $\begin{array}{l}\text { A2 (TD Social, A Favor): Es verdad que la efectividad de las } \\
\text { vacunas es diversa y que en ésta influye el sistema } \\
\text { inmunitario de cada uno [Desventaja]. }\end{array}$ \\
\hline & 0 & $\begin{array}{l}\text { No hace referencia a } \\
\text { ninguna desventaja de } \\
\text { la postura defendida }\end{array}$ & $\begin{array}{l}\text { O18 (TD Personal, A Favor): Al ponerle la vacuna contra el } \\
\text { VPH, la probabilidad de tener ese virus en el futuro } \\
\text { desciende del todo. Además, la razón de ponérsela tan joven } \\
\text { es clara, antes de empezar a tener relaciones sexuales su } \\
\text { cuerpo estará preparado frente al virus. Por eso le pondría } \\
\text { la vacuna. }\end{array}$ \\
\hline \multirow{3}{*}{$\begin{array}{l}\text { Posición } \\
\text { contraria }\end{array}$} & 2 & $\begin{array}{l}\text { Hace referencia y refuta } \\
\text { a alguna ventaja } \\
\text { (dato/justificación) de } \\
\text { la postura contraria }\end{array}$ & $\begin{array}{l}\text { A13 (TD Social, A Favor): Aunque creo que los } \\
\text { progenitores pueden tener el derecho a decidir sobre la } \\
\text { salud de sus hijos/as, y que dicho derecho debe respetarse } \\
\text { [Posición contraria], creo que el respeto a los demás debe ser } \\
\text { fundamental y que las decisiones propias no deberían poner } \\
\text { en riesgo la salud de los demás o sus vidas jamás } \\
\text { [Refutación]. }\end{array}$ \\
\hline & 1 & $\begin{array}{l}\text { Hace referencia a la } \\
\text { postura contraria }\end{array}$ & $\begin{array}{l}\text { A2 (TD Personal, En Contra): Es verdad que si [le pongo la } \\
\text { vacuna y] sale todo bien [Posición contraria], la chica tendrá } \\
\text { más ventajas que inconvenientes. }\end{array}$ \\
\hline & 0 & $\begin{array}{l}\text { No hace referencia a la } \\
\text { postura contraria }\end{array}$ & $\begin{array}{l}\text { O18 (TD Personal, A Favor): Al ponerle la vacuna contra el } \\
\text { VPH, la probabilidad de tener ese virus en el futuro } \\
\text { desciende del todo. Además, la razón de ponérsela tan joven } \\
\text { es clara, antes de empezar a tener relaciones sexuales su } \\
\text { cuerpo estará preparado frente al virus. Por eso le pondría } \\
\text { la vacuna. }\end{array}$ \\
\hline
\end{tabular}

En los casos en que se determinó la capacidad de tener en cuenta las limitaciones, se consideró tanto la referencia a las desventajas como a la posición contraria. Se entendió que es capaz aquel estudiante que al menos alcanzó un nivel 1 en cualquiera de los dos criterios. De manera análoga, se consideró que aquel estudiante que alcanzó un nivel 2 en cualquiera de dichos criterios demostró ser capaz de realizar una refutación.

En base a los criterios explicados en la tabla 2, se asignó un nivel en cada criterio a cada respuesta escrita por los y las estudiantes en las actividades de Toma de Decisión, así como a la 
actuación de cada estudiante en la discusión grupal de la Fase 4 en la TD Social. El nivel asignado correspondió al nivel más alto de los argumentos que aportó.

\section{Relación entre el modelo SI alcanzado y la calidad de la argumentación}

La cuestión sobre la relación entre el nivel de modelo de SI construido por el alumnado durante la secuencia didáctica y el nivel de argumentación manifestado, se abordó de diversas maneras:

- Se estudió la calidad de los argumentos esgrimidos en función de la categoría en que se situaba el alumnado respecto a la expresión del modelo.

- Desde un punto de vista procesual, se analizó la referencia al modelo durante el proceso de argumentación, así como el papel desempeñado por el modelo en tal proceso.

Para categorizar el tipo de modelo, se tuvieron en cuenta los niveles de modelo de SI expresados en las distintas preguntas. Los niveles de modelo de SI se determinaron (Uskola, Burgoa y Maguregi 2018) en función de las características del modelo de ser vivo (referencia a la estructura, a los procesos, a los cambios a lo largo del tiempo). Se establecieron 4 niveles (SI0-SI3), que se describen en la tabla 3.

Tabla 3. Niveles de modelo de Sistema Inmunológico.

\begin{tabular}{|c|c|}
\hline Nivel & Descripción \\
\hline SI3 & El cuerpo produce anticuerpos y éstos actúan frente al antígeno al producirse y en el futuro \\
SI2 & El cuerpo produce defensas o anticuerpos \\
SI1 & El cuerpo posee defensas \\
SI0 & El cuerpo es inerte \\
\hline
\end{tabular}

SI2 y SI3 son los niveles que muestran un cierto grado de construcción del modelo (Maguregi, Uskola y Burgoa 2017) y son los que se tuvieron en cuenta para este trabajo. Dado que hubo tres preguntas en las Fases inicial y final en las que el alumnado expresó el modelo, se crearon 4 categorías (M1-M4) para evaluar las respuestas a las tres preguntas de forma conjunta. La categoría M1 es la más baja. Para las categorías M2 y M3 se tuvieron en cuenta las respuestas de nivel SI2. En la categoría M2 se situaron los y las estudiantes que llegaron a un nivel SI2 en dos de las tres preguntas, es decir, tenían un modelo de cuerpo activo, si bien en algún caso, por ejemplo, en la pregunta que requiere una transferencia lejana, no lo expresaron. En la categoría M3 se incluyeron las y los que son capaces de generalizar el modelo de cuerpo activo a todos los contextos, es decir, que llegaron a un nivel SI2 en las tres respuestas. En la categoría M4 se situaron las y los estudiantes que tenían un modelo de cuerpo como sistema que cambia y actúa a lo largo del tiempo, aunque en algún caso no lo expresaron, es decir, aquellas y aquellos cuyas respuestas se categorizaron en el nivel SI3 en dos de las tres preguntas.

\section{Resultados}

En primer lugar, se dan los datos del posicionamiento del alumnado respecto a poner vacunas (TD Personal) y a su obligatoriedad (TD Social) (Tabla 4). A continuación, se exponen los resultados obtenidos respecto a cada pregunta de investigación. 
Tabla 4. Posicionamiento adoptado por los estudiantes en las distintas actividades de Toma de Decisión (TD)

\begin{tabular}{|c|c|c|c|c|}
\hline \multirow{2}{*}{ Actividad } & Posicionamiento & $\begin{array}{c}\text { Fase 1 } \\
(\mathrm{N}=72)\end{array}$ & $\begin{array}{c}\text { Fase 4-discusión } \\
(\mathrm{N}=61)\end{array}$ & $\begin{array}{c}\text { Fase } 4 \\
(\mathrm{~N}=72)\end{array}$ \\
\hline \multirow{2}{*}{ TD Personal } & A favor (Af) & $93 \%$ & - & $82 \%$ \\
\cline { 2 - 5 } & En contra (Ec) & $4 \%$ & - & $14 \%$ \\
\hline \multirow{2}{*}{ TD Social } & A favor (Af) & $36 \%$ & $33 \%$ & $71 \%$ \\
\cline { 2 - 5 } & En contra (Ec) & $63 \%$ & $29 \%$ \\
\hline
\end{tabular}

\section{Calidad de la argumentación}

En la figura 1 se muestran los promedios de nivel (0-2) que, según cada criterio (Justificación, Desventajas y Posición contraria), mostraron los y las estudiantes en los argumentos escritos en las actividades de Toma de Decisión de las Fases 1 (Exploración) y 4 (Transferencia) de la secuencia.

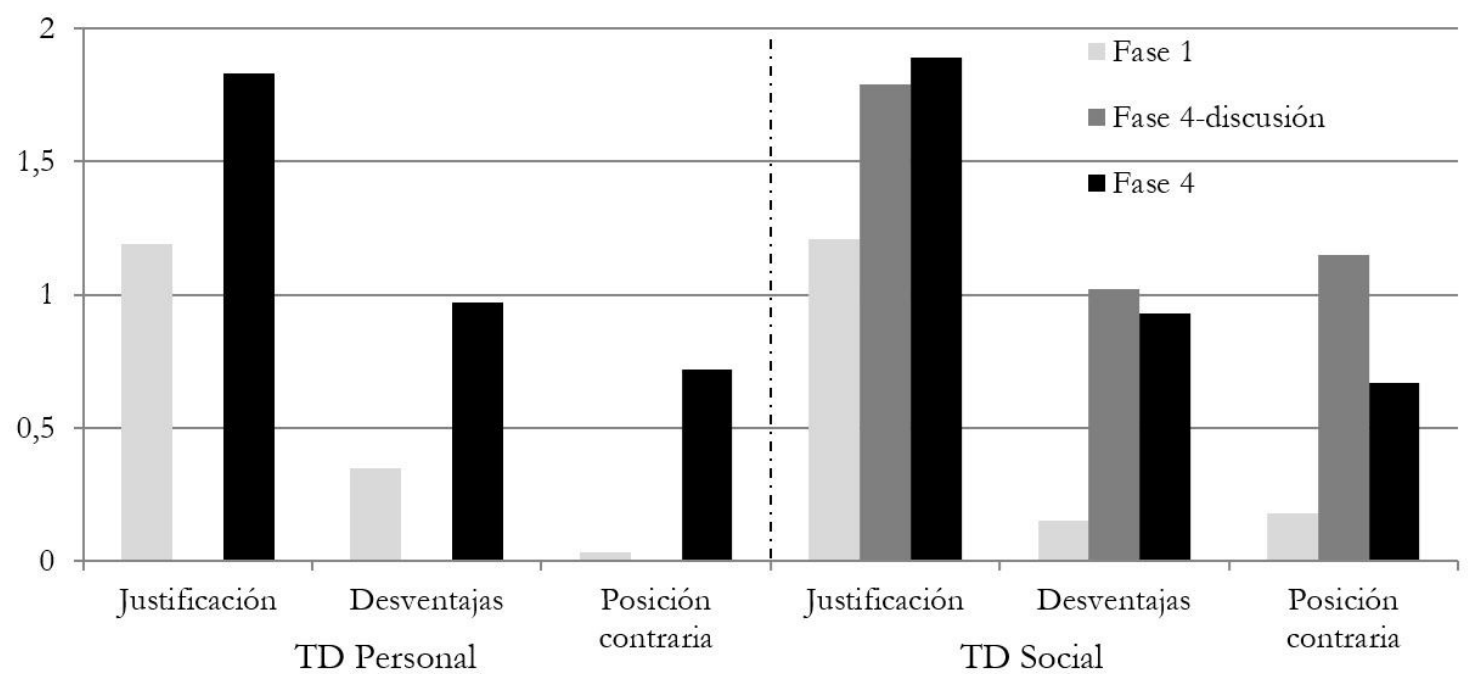

Figura 1. Promedios de nivel mostrados por los y las estudiantes en los argumentos elaborados en las Tomas de Decisión

Los datos de la figura 1 muestran un aumento en el nivel de desempeño en argumentación en ambas TD. Se observa que el criterio en que más destacaron es Justificación, con un $32 \%$ de estudiantes que dieron más de un dato y/o justificación en la Fase 1 y un 85\% (TD Personal) $-92 \%$ (TD Social) en la Fase 4. En el caso de la TD Personal, los tamaños de efecto fueron $\mathrm{d}=0,96$ para las justificaciones, $\mathrm{d}=0,65$ para las desventajas y $\mathrm{d}=0,78$ para la posición contraria. En el caso de la TD Social d=1,02, d=0,91, y d=0,55 respectivamente.

Por otro lado, en cuanto a las refutaciones, en la TD Personal, el porcentaje de estudiantes que realizó una refutación (es decir, que alcanzó un nivel 2 bien respecto a las Desventajas, bien a la Posición contraria) pasó de un 4\% en la Fase 1 a un 47\% en la Fase 4 (d=0,76). En la TD Social pasaron de ser un $4 \%$ en la Fase 1 a un $43 \%$ en la Fase $4(d=0,68)$.

Para caracterizar de manera más detallada el desarrollo del desempeño en argumentación, se pueden observar los resultados de las discusiones (Fase 4-discusión). En la Figura 1 se puede ver que, en el caso de las referencias a las Desventajas y a la Posición contraria, fue mayor el nivel en la discusión. Por otro lado, el 51\% de los y las estudiantes demostró ser capaz de realizar una refutación en esta actividad, frente al 5\% en los argumentos escritos en la Fase 1 y al 43\% en la Fase 4. En el siguiente extracto se pueden ver ejemplos: 
13 O27: Yo no creo que deba ser obligatorio vacunarse. Creo que debe decidir cada uno. [Justificación Decisión Personal]

14 O4: Bueno, cada uno... Cuando eres niño al final elegirán tus padres. [Refuta a O27]

$\cdots$

25 O4: Pero sus padres no pueden decidir sobre otros niños... [Justificación Salud pública]

26 O27: Pero los otros niños, si están vacunados, no se infectarán. [Refuta a O4]

En la tabla 5 se muestran los resultados en función del posicionamiento adoptado (a favor Af- o en contra -Ec- de poner vacunas en la TD Personal, y de su obligatoriedad en la TD Social).

Tabla 5. Promedios de nivel en los tres criterios de evaluación de argumentos y porcentaje de refutaciones en las TD, según el posicionamiento adoptado.

\begin{tabular}{|c|c|c|c|c|c|c|}
\hline TD & Fase & Posicionamiento & Justificación & Desventajas & $\begin{array}{c}\text { Postura } \\
\text { contraria }\end{array}$ & Refutaciones \\
\hline \multirow{4}{*}{ TD Personal } & \multirow{2}{*}{ Fase 1} & Af & 1,239 & 0,343 & 0,03 & $5 \%$ \\
\hline & & Ec & 1 & 0.67 & 0 & $0 \%$ \\
\hline & \multirow{2}{*}{ Fase 4} & Af & 1,898 & 1 & 0,763 & $53 \%$ \\
\hline & & $\mathrm{Ec}$ & 1,6 & 0,9 & 0,5 & $20 \%$ \\
\hline \multirow{6}{*}{ TD Social } & \multirow{2}{*}{ Fase 1} & Af & 1,385 & 0,077 & 0,385 & $12 \%$ \\
\hline & & $\mathrm{Ec}$ & 1,133 & 0,2 & 0,067 & $0 \%$ \\
\hline & \multirow{2}{*}{$\begin{array}{l}\text { Fase 4- } \\
\text { discusión }\end{array}$} & Af & 1,73 & 1,146 & 1,292 & $61 \%$ \\
\hline & & Ec & 1,9 & 0,75 & 0,85 & $30 \%$ \\
\hline & \multirow{2}{*}{ Fase 4} & Af & 1,92 & 1,02 & 0,784 & $53 \%$ \\
\hline & & Ec & 1,81 & 0,714 & 0,381 & $19 \%$ \\
\hline
\end{tabular}

Si se observan los datos de la tabla 5, para una misma TD y una misma Fase, en la mayoría de los casos en que hubo diferencias en función del posicionamiento, en los aspectos considerados en el desempeño en argumentación (Justificación, Desventajas, Posición contraria y Refutaciones), éstas se decantaron del lado de las y los estudiantes que defendían las vacunas. De hecho, se hallaron correlaciones estadísticamente significativas en algunos casos entre defender las vacunas y el nivel en determinado criterio: Justificación en TD Personal en Fase 1 ( $r=0,308$ significativa al 0,01), Justificación en TD Personal en Fase 4 $(\mathrm{r}=0,386$ significativa al 0,01), Justificación en TD Social en Fase $1(\mathrm{r}=0,256$ significativa al 0,05), Posición contraria en TD Social en Fase 1 ( $\mathrm{r}=0,314$ significativa al 0,01), Desventajas $(\mathrm{r}=0,253$ significativa al 0,05) y Posición contraria en la discusión de la TD Social $(\mathrm{r}=0,272$ significativa al 0,05). Esto es, las y los que defendieron la vacunación aportaron más datos y justificaciones (puntuaron más alto en Justificación en todas las TD), se mostraron más conscientes de las desventajas de su opción (puntuaciones más altas en Fase 4 en Desventajas) y de las justificaciones contrarias (puntuación más alta en Posición contraria), pero también fueron más capaces de refutarlas. Destaca la diferencia en la formulación de refutaciones, en la que el porcentaje de estudiantes que estaba a favor dobló al del que estaba en contra.

\section{Relación entre el modelo SI alcanzado y la calidad de la argumentación}

Calidad de los argumentos según categoría

En la tabla 6 se muestra el número y porcentaje de estudiantes en cada categoría establecida según el nivel del modelo de SI mostrado en las tres preguntas de cada Fase. 
Tabla 6. Estudiantes en las categorías de modelo, en las Fases 1 y 4.

\begin{tabular}{|l|l|l|}
\hline Categoría & Fase 1 & Fase 4 \\
\hline M4 & $3(4,1 \%)$ & $13(18 \%)$ \\
\hline M3 & $2(2,8 \%)$ & $37(51,4 \%)$ \\
\hline M2 & $36(50 \%)$ & $18(25 \%)$ \\
\hline M1 & $31(43 \%)$ & $4(5,5 \%)$ \\
\hline
\end{tabular}

En las figuras 2 y 3 se muestran los niveles de argumentación mostrados por los y las estudiantes de cada categoría, en la TD Personal y en la TD Social, respectivamente. En cada Fase se obviaron las categorías con menos de tres estudiantes: M3 y M4 en la Fase 1, y M1 en la Fase 4.

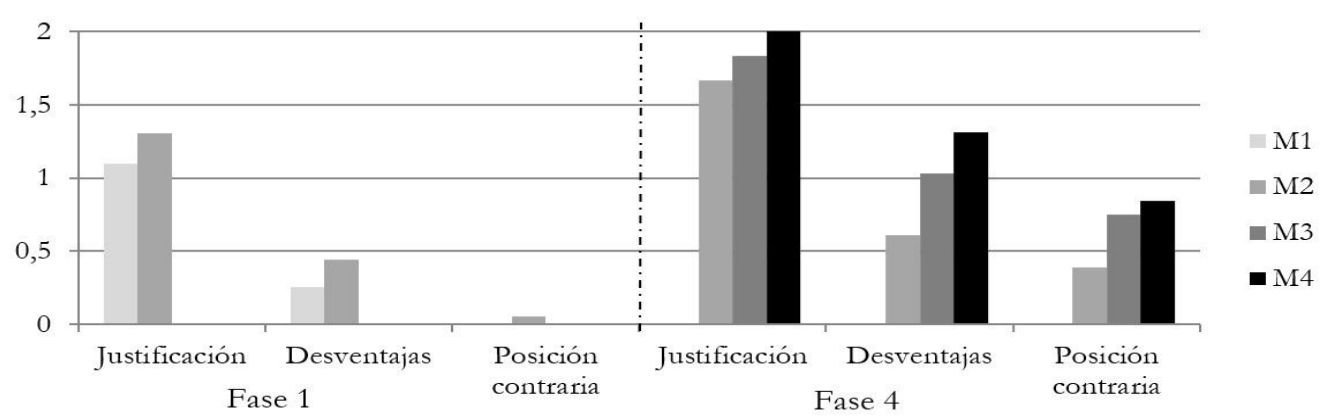

Figura 2. Calidad de los argumentos esgrimidos por los y las estudiantes de las distintas categorías en la TD Personal.

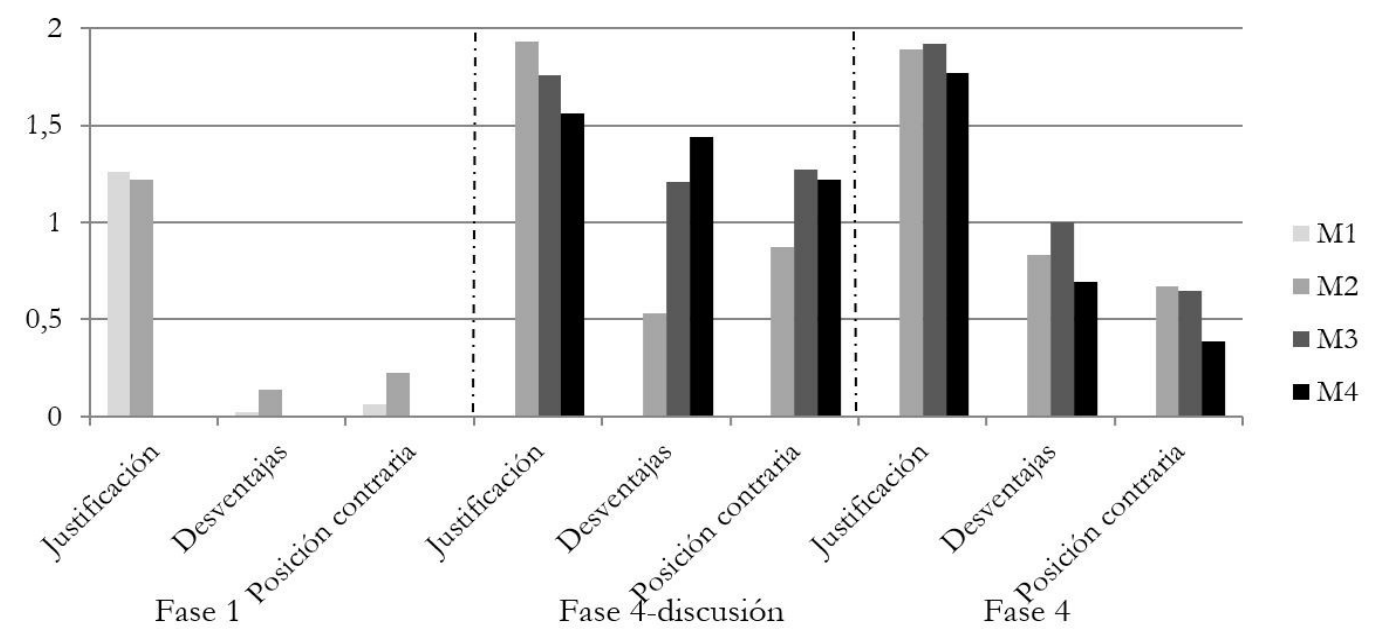

Figura 3. Calidad de los argumentos esgrimidos por las y los estudiantes de las distintas categorías en la TD Social.

Como se puede ver los resultados muestran que en la TD Personal, los y las estudiantes argumentaron mejor, en base a todos los criterios, cuanto mayor era su categoría $\mathrm{M}$ en una Fase dada. Así, la categoría correlacionó con Posición contraria $(0,246$ al 0,05) en la Fase 1, y con Justificación $(0,248$ al 0,05) y Desventajas $(0,283$ al 0,05) en la Fase 4. En cuanto a la TD Social, este patrón pareció cumplirse, aunque de forma no tan clara, en la Fase 1 y entre M2 y M3 en la Fase 4 (correlación entre la categoría y Desventajas $(0,413$ al 0,01) en la discusión). Sin embargo, el alumnado de M4 argumentó peor de lo que cabría esperar, según todos los criterios. 
La tabla 7 recoge todos los resultados pormenorizados en función de la categoría en la expresión del modelo y del posicionamiento adoptado (a favor -Af- o en contra -Ec- de poner vacunas en la TD Personal, y de su obligatoriedad en la TD Social). Para facilitar el análisis, se obviaron los datos que corresponden a menos de 3 estudiantes.

Tabla 7. Promedios de niveles en argumentación y referencia al modelo en las Tomas de Decisión (TD), según categoría de expresión del modelo.

\begin{tabular}{|c|c|c|c|c|c|c|c|c|}
\hline & Fases & $\begin{array}{c}\text { Categorí } \\
\text { as }\end{array}$ & Posiciones & $\begin{array}{c}\text { Justificacio } \\
\text { nes }\end{array}$ & $\begin{array}{c}\text { Desventaja } \\
\mathrm{s}\end{array}$ & Postura & Refutaciones & Referencia \\
\hline \multirow{16}{*}{$\begin{array}{c}\text { TD } \\
\text { Personal }\end{array}$} & \multirow{8}{*}{ Fase 1} & \multirow{2}{*}{ M1 } & Af $(\mathrm{N}=29)$ & 1,14 & 0,24 & 0 & 0 & 0 \\
\hline & & & $\mathrm{Ec}(\mathrm{N}=1)$ & & & & & \\
\hline & & \multirow{2}{*}{ M2 } & Af $(\mathrm{N}=34)$ & 1,32 & 0,44 & 0,06 & $9 \%$ & 0,15 \\
\hline & & & $\mathrm{Ec}(\mathrm{N}=2)$ & & & & & \\
\hline & & \multirow{2}{*}{ M3 } & Af $(\mathrm{N}=1)$ & & & & & \\
\hline & & & $\operatorname{Ec}(N=0)$ & & & & & \\
\hline & & \multirow{2}{*}{ M4 } & Af $(N=3)$ & & & & & \\
\hline & & & $\mathrm{Ec}(\mathrm{N}=0)$ & & & & & \\
\hline & \multirow{8}{*}{ Fase 4} & \multirow{2}{*}{ M1 } & Af $(N=3)$ & 2 & 1 & 1,67 & $67 \%$ & 0,67 \\
\hline & & & $\mathrm{Ec}(\mathrm{N}=0)$ & & & & & \\
\hline & & \multirow{2}{*}{ M2 } & Af $(\mathrm{N}=14)$ & 1,71 & 0,57 & 0,43 & $36 \%$ & 0,57 \\
\hline & & & Ec $(N=4)$ & 1,5 & 0,75 & 0,25 & $25 \%$ & 0,25 \\
\hline & & \multirow{2}{*}{ M3 } & Af $(\mathrm{N}=30)$ & 1,93 & 1,07 & 0,8 & $60 \%$ & 0,60 \\
\hline & & & $\mathrm{Ec}(\mathrm{N}=5)$ & 1,6 & 1 & 0,6 & $20 \%$ & 0 \\
\hline & & \multirow{2}{*}{ M4 } & Af $(\mathrm{N}=12)$ & 2 & 1,33 & 0,83 & $58 \%$ & 1,17 \\
\hline & & & $\mathrm{Ec}(\mathrm{N}=1)$ & & & & & \\
\hline \multirow{16}{*}{ TD Social } & \multirow{8}{*}{ Fase 1} & \multirow{2}{*}{ M1 } & Af $(\mathrm{N}=13)$ & 1,39 & 0,08 & 0,15 & 0 & 0 \\
\hline & & & $\operatorname{Ec}(N=18)$ & 1,17 & 0,28 & 0 & 0 & 0 \\
\hline & & \multirow{2}{*}{ M2 } & Af $(\mathrm{N}=11)$ & 1,45 & 0,09 & 0,45 & $18 \%$ & 0,18 \\
\hline & & & $\mathrm{Ec}(\mathrm{N}=24)$ & 1,17 & 0,17 & 0,13 & 0 & 0 \\
\hline & & \multirow{2}{*}{ M3 } & Af $(N=1)$ & & & & & \\
\hline & & & $\mathrm{Ec}(\mathrm{N}=1)$ & & & & & \\
\hline & & \multirow{2}{*}{ M4 } & Af $(\mathrm{N}=1)$ & & & & & \\
\hline & & & $\mathrm{Ec}(\mathrm{N}=2)$ & & & & & \\
\hline & \multirow{8}{*}{ Fase 4} & \multirow{2}{*}{ M1 } & Af $(\mathrm{N}=4)$ & 2 & 1,5 & 1,75 & $100 \%$ & 0 \\
\hline & & & $\mathrm{Ec}(\mathrm{N}=0)$ & & & & & \\
\hline & & \multirow{2}{*}{ M2 } & Af $(\mathrm{N}=12)$ & 2 & 1 & 0,75 & $50 \%$ & 0,25 \\
\hline & & & $\mathrm{Ec}(\mathrm{N}=6)$ & 1,67 & 0,5 & 0,5 & $33 \%$ & 0,50 \\
\hline & & \multirow{2}{*}{ M3 } & Af $(N=26)$ & 1,92 & 1,08 & 0,73 & $58 \%$ & 0,54 \\
\hline & & & $\operatorname{Ec}(\mathrm{N}=11)$ & 1,91 & 0,82 & 0,45 & $18 \%$ & 0,27 \\
\hline & & \multirow{2}{*}{ M4 } & Af $(\mathrm{N}=9)$ & 1,78 & 0,67 & 0,56 & $33 \%$ & 0,44 \\
\hline & & & $\mathrm{Ec}(\mathrm{N}=4)$ & 1,75 & 0,75 & 0 & 0 & 0 \\
\hline
\end{tabular}


Si se observan los datos de la tabla 7 , en la que los datos se ordenan teniendo en cuenta el posicionamiento, se ve que en general se mantiene el patrón mencionado sobre la influencia de la categoría. Así, por ejemplo, entre los que defendieron las vacunas en la TD Personal, en la Fase 1 los de M2 argumentaron mejor que los de M1 según los 4 aspectos. Y lo mismo se puede decir en la TD Social; no hubo diferencias entre los que estaban en M1 y M2 entre los que se manifestaron en contra en la TD Social. En la Fase 4 de la TD Personal se mantuvo que los de M4 argumentaron mejor que los de M3 y éstos que los de M2 entre los que estaban a favor y ligeramente entre los que estaban en contra. En la Fase 4 de la TD Social los datos fueron más variables y resulta difícil ver una tendencia clara.

Referencias al modelo en el proceso de argumentación

Los resultados sobre si hicieron referencia o no al modelo en la tomas de decisión se muestran en la tabla 8.

Tabla 8. Distribución de los estudiantes en función de su referencia al modelo en los argumentos.

\begin{tabular}{|c|c|c|c|c|}
\hline \multirow{2}{*}{ TD } & \multirow{2}{*}{ Fase } & \multicolumn{3}{|c|}{ Nivel de referencia del modelo } \\
\cline { 2 - 5 } & F No hacen & referencia al modelo & $\begin{array}{c}\text { Hacen referencia al } \\
\text { modelo }\end{array}$ & $\begin{array}{c}2 \text { Utilizan la } \\
\text { referencia al modelo } \\
\text { en el argumento }\end{array}$ \\
\hline \multirow{2}{*}{ TD Personal } & Fase 1 & $69(96 \%)$ & $1(1 \%)$ & $2(3 \%)$ \\
\cline { 2 - 5 } & Fase 4 & $49(68 \%)$ & $1(1 \%)$ & $21(29 \%)$ \\
\hline \multirow{2}{*}{ TD Social } & Fase 1 & $71(99 \%)$ & 0 & $6(8 \%)$ \\
\cline { 2 - 5 } & Fase 4-discusión & $47(65 \%)$ & $8(11 \%)$ & $11(15 \%)$ \\
\cline { 2 - 5 } & Fase 4 & $56(78 \%)$ & $5(7 \%)$ & $1 \%)$ \\
\hline
\end{tabular}

He aquí dos ejemplos, uno de cada TD, en los que las estudiantes utilizaron la referencia al modelo para su argumentación.

A26 (M3, TD Personal, A favor) (...) Aunque la hija sea joven (por lo que podemos pensar que tiene menos probabilidades de sufrir enfermedades que se transmiten sexualmente) será mejor ponerle la vacuna para que pueda hacerle frente a la enfermedad.

Los daños que puede provocar este virus (...) son graves, por lo que si el sistema inmune de la chica está preparado (lo que se consigue con la vacuna) si alguna vez se le transmite ese virus, evitaríamos los daños y el contagio. (...). A través de las vacunas el cuerpo pone en marcha los sistemas de defensa para hacer frente a los virus y bacterias. Además, gracias a unas células de linfocitos especiales, el cuerpo guarda su memoria, por lo que aunque la chica sea joven, en el futuro, cuando tenga mayor probabilidad de contagiarse con ese virus (...), su sistema inmune tendrá preparados sus mecanismos de defensa.

A12 (M2, TD Social, En contra) (...) No creo que hubiera pandemia, porque el efecto de la bacteria sobre los niños vacunados sería suave, gracias a las células memoria del sistema inmumológico. (...)

Tal como aparece reflejado, la referencia al modelo en la argumentación en las actividades analizadas fue muy baja, aunque mejoró en la Fase 4 respecto a la Fase 1, siendo el tamaño de efecto moderado ( $\mathrm{d}=0,52$ para TD Personal, $\mathrm{d}=0,44$ para TD Social). En la tabla 7 se muestran los promedios en función del posicionamiento y la categoría.

Los resultados obtenidos inducen a pensar que, por una parte, el posicionamiento fue un factor determinante, es decir, utilizaron más el conocimiento en sus argumentos los y las estudiantes que estaban a favor de las vacunas tanto en la TD Personal como en la TD Social. Parece que la categoría influyó de forma menos clara. 


\section{Discusión}

La primera pregunta abordada por este estudio ha sido qué aspectos de la argumentación desarrollaron los y las estudiantes a lo largo de una secuencia de actividades sobre el sistema inmunológico y cómo los mostraban en tomas de decisión de ámbito personal y social. Los criterios y niveles propuestos para la evaluación de los argumentos en las Tomas de Decisión analizadas, han permitido determinar cómo se desarrolló la capacidad de argumentar en sus distintas facetas. Así, se observa que el criterio en que más destacaron desde un inicio y, especialmente en la Fase 4, es Justificación. Por el contrario, la faceta que resultó más complicada fue la referencia a la Posición contraria, resultado que concuerda con el de Felton, García-Milá y Gilabert (2009). La participación en las actividades parece que favoreció el desarrollo de todas las facetas, ya que en la Fase 4 los resultados fueron mejores que en la Fase 1 para todos los criterios de calidad de la argumentación. Uno de los aspectos clave relacionados con la calidad del argumento es la capacidad de formular refutaciones (Erduran, Simon y Osborne 2004) a un argumento. En la Fase 4 aumentó el porcentaje de estudiantes que refutó argumentos, si bien hay dos aspectos que merecen consideración que pudieron favorecer la aparición de resultados diversos: el que se tratara de argumentos esgrimidos por escrito o en discusiones, y el posicionamiento.

$\mathrm{El}$ análisis de las discusiones permitió observar que las discusiones entre estudiantes fueron las que permitieron al alumnado desempeñar mejor varios aspectos de la competencia argumentativa. Este mejor desempeño en argumentación en discusiones orales que en trabajos escritos fue hallado en otras investigaciones (Bravo 2012).

Así, es en las discusiones cuando el alumnado tiene oportunidad de refutar los datos o justificaciones de los argumentos contrarios de una manera más clara, ya que los exponen sus compañeros/as, es decir se hacen explícitos. Por el contrario, cuando escriben individualmente su decisión, tienen que refutar a un interlocutor imaginario. Las diferencias en los resultados obtenidos fueron, sin embargo, menores de lo esperado: El porcentaje de estudiantes que realizó refutaciones en la discusión fue solo ligeramente superior al que lo hizo en el escrito individual final. Esto pudo ser debido a que la actividad escrita fue realizada inmediatamente después de la discusión, lo que facilitó al alumnado tener muy presentes las justificaciones contrarias. Se necesitarían más datos, y de momentos más alejados de la discusión, para determinar si la mejora dada en la discusión en cuanto a las Desventajas y Posición contraria tuvo un efecto a un plazo más largo.

El posicionamiento de las y los estudiantes fue un factor clave en la calidad de sus argumentos, de tal forma que aquéllos que se posicionaron a favor de poner vacunas (TD Personal) y/o de su obligatoriedad (TD Social) formularon, salvo alguna excepción, argumentos de mayor nivel en todos los criterios. Este resultado se corroboró también aún teniendo en cuenta la categoría de expresión del modelo y comparando estudiantes en el mismo nivel. Esto es, los que estaban a favor dieron más datos y justificaciones, fueron más conscientes de las desventajas de su opción y de las justificaciones contrarias, pero también se mostraron más capaces de refutarlas. Destaca de forma notable la diferencia en un aspecto tan importante como la capacidad de formular refutaciones, en la que el porcentaje de estudiantes que estaba a favor dobló al del que estaba en contra.

Se podría pensar que dado que la secuencia de actividades facilitó que construyeran conocimiento sobre el funcionamiento del SI, este mayor conocimiento, reflejado en las expresiones del modelo SI, habría servido para justificar y dar pruebas a los y las estudiantes que defendían las vacunas. Esta hipótesis de que puede haber relación entre la construcción del modelo y la capacidad de argumentar fue objeto de la segunda pregunta abordada por este 
trabajo. Los análisis realizados para dar respuesta a la pregunta fueron varios y los resultados, diversos.

Así, en algunos casos, como en la TD Personal y algunos de la TD Social se observa que, a mayor categoría en la expresión del modelo, mejor argumentación en todos los criterios, lo que estaría en consonancia por lo hallado por Baytelman et al. (2020) respecto al conocimiento previo. De todas formas, hay que reconocer que resulta inexplicable la actuación de los y las estudiantes de la categoría más alta, M4, en la Fase 4. Este alumnado demostró haber construido un modelo de SI completo, sus respuestas fueron de nivel SI3 en un mínimo de dos de las tres preguntas de transferencia de conocimiento. En la TD Personal destacaron igualmente en todos los criterios de calidad de argumentación; sin embargo, en la TD Social argumentaron en un nivel inferior a los del M3 (definido por llegar a un nivel SI2 en las tres preguntas) en todos los criterios. Si se enmarca la discusión en el Modelo de Umbral propuesto por Sadler y sus colegas (Sadler y Donnelly 2006; Sadler y Fowler 2006), esto supondría que puede haber un umbral entre M2 y M3 y que al pasar a estar en un nivel M3, la calidad de la argumentación mejora respecto a estar en un nivel M2; pero que puede no haberlo entre M3 y M4, de tal manera que estar en un nivel M4 no necesariamente supone un incremento en la calidad de la argumentación.

Dado que el posicionamiento se mostró como un factor distintivo a la hora de argumentar, se analizaron los datos teniendo en cuenta tanto el posicionamiento como la categoría, y se observó que aún teniendo en cuenta la influencia del posicionamiento, la categoría en la expresión del modelo era un factor que parecía marcar cierta diferencia a la hora de argumentar. Este resultado encajaría con lo deseable desde la enseñanza de las ciencias, que los y las estudiantes integren el conocimiento científico adquirido y lo utilicen en sus tomas de decisión, de tal manera que sean capaces de justificarlas y de ser más críticos y más críticas.

Sin embargo, cuando se profundizó en el análisis de cómo se integró ese conocimiento en los argumentos, hay que reconocer que los resultados fueron decepcionantes. Parece que hubo cierta mejoría a lo largo de la secuencia, que utilizaron en sus argumentos más el modelo de SI quienes defendieron las vacunas y quienes se situaban en una mayor categoría de expresión del modelo. Lo que es preocupante es que, a la hora de tomar una decisión sobre un tema relacionado con la salud, en el que están implicados los conocimientos científicos que habían tratado a lo largo de la secuencia, estudiantes que habían demostrado haber construido dicho conocimiento en un alto grado e incluso habían sido capaces de realizar una transferencia lejana del mismo en preguntas conceptuales (Uskola, Burgoa y Maguregi 2018), no hicieran referencia a dicho conocimiento. Nielsen (2012) observó que los y las estudiantes apelaban al conocimiento cuando éste apoyaba su posicionamiento. En este caso parece que ni siquiera aquellos que estaban a favor de la vacunación obligatoria apelaron al conocimiento científico de forma notable para apoyar su opción. En un estudio anterior, Lima, Jiménez-Aleixandre y Mortimer (2010), analizaron las referencias al modelo de evolución biológica en los argumentos producidos por estudiantes de secundaria, y observaron que los y las estudiantes sí hacían referencia a los distintos aspectos del modelo en sus argumentos. Hay que tener en cuenta que las actividades en torno a las que desarrollaban argumentos eran científicas, mientras que en este estudio se han analizado Tomas de Decisión en torno a temas sociocientíficos más o menos controvertidos. Así lo es la obligatoriedad de la vacunación (TD Social) en que sólo un 15\% del alumnado utilizó las referencias al modelo SI en sus argumentos. Este resultado concuerda con el de otras investigaciones que han señalado que en cuestiones sociocientíficas otro tipo de consideraciones adquieren mayor relevancia que el conocimiento científico (Nielsen 2012; Ratcliffe 1997). 
Hay otros resultados que merecen resaltarse. Por un lado, se observa una diferencia en cuanto a la referencia al modelo entre la TD Personal y la TD Social, siendo mayor en la TD Personal. Esto concuerda con lo observado en cuanto al tipo de justificaciones empleadas (Uskola, Maguregi y Burgoa 2017), ya que en la TD Personal la principal justificación era la Salud Individual, mientras que en la TD Social era la Salud Pública en el caso de quienes defendían la obligatoriedad, y la Libertad Individual por parte de quienes se oponían. Parece confirmarse, por tanto, que en el caso de la TD Social la lejanía del contexto es aún mayor para los y las estudiantes, respecto al conocimiento científico.

Por otro lado, hubo diferencia en la referencia al modelo dependiendo del posicionamiento, favorable a quienes defendían las vacunas y su obligatoriedad. Esto puede indicar que quienes estaban en contra, a pesar de que pudieron haber construido un modelo de SI bastante completo, pudieron pensar que la alusión a dicho conocimiento jugaba en su contra. Trabajar en las clases de ciencias cuestiones relativas a la calidad de la argumentación, como el hecho de que referirse a las desventajas de la propia opción es un indicador de alta competencia argumentativa podría ayudar a que los estudiantes incorporaran a sus argumentos y tomas de decisión la mayor cantidad de información y conocimiento disponible.

Dado que el tema es el mismo en todas las actividades, la vacunación, esta dificultad puede venir dada porque sitúen el contexto en un entorno cotidiano, en el que utilizan justificaciones que en algunos casos tienen que ver con el conocimiento científico pero de forma poco profunda, sin apelar a cómo funciona el sistema inmunológico, y que en otros casos no tienen relación alguna con el conocimiento científico, como el apelar a las libertades individuales (Uskola, Maguregi y Burgoa 2017). El hecho de apelar a otro tipo de justificaciones es propio de las controversias sociocientíficas; pero el conocimiento científico fundamentado debería ser una de las miradas importantes tenidas en cuenta a la hora de posicionarse bien a favor o bien en contra de decisiones relacionadas con la salud a nivel personal y sobre todo a nivel colectivo.

\section{Conclusiones}

De este estudio se puede concluir que, en las tomas de decisión relacionadas con la salud, los y las estudiantes han sido capaces de desarrollar distintos aspectos de la competencia argumentativa, capacidad incluida en la competencia científica. Los datos del estudio fueron limitados, y las conclusiones no pretenden ser generalizadas. Otra de las limitaciones del estudio es que sería deseable disponer de datos de más actividades en las que los y las estudiantes hubieran tenido la oportunidad de integrar el conocimiento científico y la capacidad de argumentación. En este estudio se ha analizado la construcción de conocimiento en actividades en las que transferían el conocimiento a un contexto cercano o lejano; pero que no requería argumentación explícitamente, y por otra parte, actividades de tomas de decisión en las que parece haber prevalecido la componente personal o social. Sería interesante diseñar e investigar contextos que requieran argumentación, pero más directamente relacionada con el conocimiento científico. Esto permitiría analizar y contrastar de qué manera se integran cuando no son los valores sociales y personales los que prevalecen. La investigación, de todas formas, estaba centrada en cómo se integran conocimiento y argumentación en las tomas de decisión relacionadas con la vida cotidiana. En este sentido, ha aportado datos para la reflexión acerca de la integración de distintos tipos de capacidades científicas. Los resultados muestran que las personas que construyeron un modelo de SI más acorde al modelo de ser vivo demostraron mayor competencia argumentativa. Sin embargo, no fueron capaces de conectar y utilizar la referencia a tal conocimiento en sus argumentos durante las tomas de decisión, es decir, no demostraron un desempeño de la competencia científica en su sentido de integración de distintos tipos de conocimientos, valores, habilidades. La integración de las 
diferentes capacidades y conocimientos, y en este caso, la integración del conocimiento científico en los argumentos es deseable para cualquier estudiante; pero lo es aún más en el caso del futuro profesorado. Los participantes en este estudio son futuro profesorado de Educación primaria, es decir, tendrán que diseñar estrategias que favorezcan una integración de capacidades que ellos mismos han encontrado dificultosa. Promover la reflexión acerca de estas dificultades y acerca de las posibilidades para superarlas será un elemento importante en su formación. La integración de diferentes capacidades y conocimientos y, en este caso, de conocimiento científico en los procesos de argumentación es una meta deseable para cualquier estudiante; pero lo es aún más en el caso del futuro profesorado. Los participantes en este estudio, futuro profesorado de Educación Primaria, tendrán que diseñar estrategias que favorezcan dicha integración, que ellos mismos han encontrado dificultosa. Por tanto, promover la reflexión acerca de estas dificultades y de las posibilidades para superarlas será un elemento importante en su formación. El reto no es sencillo, teniendo en cuenta las escasas horas de formación en didáctica de las ciencias que reciben estos estudiantes y que su punto de partida en competencia científica y didáctica suele ser bajo. Sin embargo, es un reto que merece ser afrontado.

La dificultad en la integración del conocimiento científico en los argumentos podría estar relacionada con la situación problemática en la que se requiere la toma de decisión, un contexto sociocientífico, en el que las y los estudiantes tal vez no sintieron la necesidad de apelar a su conocimiento científico. Se promulga que la finalidad del desarrollo de la competencia científica es formar una ciudadanía crítica capaz de tomar decisiones informadas en su vida diaria teniendo en cuenta el conocimiento científico, pero, a la luz de los resultados de esta investigación, se plantea una cuestión a resolver: ¿siente la ciudadanía la necesidad de poseer un conocimiento científico para poder decidir sobre cuestiones sociocientíficas? Habrá que reflexionar y trabajar para facilitar que los estudiantes, y la ciudadanía en general, vea la necesidad y la importancia de dicho fundamento científico.

\section{Agradecimientos}

Este trabajo ha sido financiado por la Ayuda a la Investigación: Mod. II Grupos de la UPV/EHU (códigos GIU19/008 y PPGA20/14).

\section{Referencias}

Baytelman A., Iordanou K., Constantinou C. P. (2020) Epistemic beliefs and prior knowledge as predictors of the construction of different types of arguments on socioscientific issues. Journal of Research in Science Teaching 57, 1199-1227.

Berland L. K., Reiser B. J. (2009) Making sense of argumentation and explanation. Science Education 93, 26-55. https://doi.org/10.1002/sce.20286

Blanco P. (2015) Modelización y argumentación en actividades prácticas de Geología en Secundaria. Tesis doctoral. Universidade de Santiago de Compostela: Santiago de Compostela.

Blanco Anaya P., Díaz de Bustamante J., Mendonça P. C. C. (2019) Las destrezas argumentativas en la evolución de modelos en una actividad de geología. Revista Eureka sobre Enseñanza y Divulgación de las Ciencias 16(3), 3105.

Bravo B. (2012) El desempeño de las competencias cientificas de uso de pruebas y modelización en un problema de gestión de recursos marinos. Tesis doctoral. Universidade de Santiago de Compostela: Santiago de Compostela. 
Böttcher F., Meisert A. (2010) Argumentation in Science Education: A Model-based Framework. Science \& Education 20, 103-140. https://doi.org/10.1007/s11191-0109304-5

Cardoso P. C., Justi R. (2014) An instrument for analyzing arguments produced in modelingbased chemistry lessons. Journal of Research in Science Teaching 51, 117-249. https://doi.org/10.1002/tea.21133

COSCE (2011). Enseñanza de las Ciencias en la Didáctica escolar para edades tempranas en España (Informe Enciende). Madrid: COSCE.

Díaz N., Jiménez-Liso M. R. (2012) Las controversias sociocientíficas: Temáticas e importancia para la educación científica. Revista Eureka sobre Enseñanza y Divulgación de las Ciencias 9, 54-70.

Erduran S., Simon S., Osborne J. (2004) TAPping into argumentation: Developments in the application of Toulmin's Argument Pattern for studying science discourse. Science Education 88, 915- 933. https://doi.org/10.1002/sce.20012

Erickson F. (1989) Métodos cualitativos de investigación sobre la enseñanza. En M. Wittrock M. (Ed.), La investigación de la enseñanza, II. Métodos cualitativos y de observación (pp.195-301). Barcelona: Paidós.

Felton M., García-Milá M., Gilabert S. (2009) Deliberation versus dispute: The impact of argumentative discourse goals on learning and reasoning in the science classroom. Informal Logic 29, 417-446.

García-Milá M., Gilabert S., Erduran S., Felton M. (2013) The effect of argumentative task goal on the quality of argumentative discourse. Science Education 97, 497-523.

Garrido A. (2016) Modelización i models en la formació inicial de mestres de primària des de la perspectiva de la pràctica cientifica. Tesis doctoral. Universitat Autònoma de Barcelona. Barcelona. Cataluña.

Gee J. P. (1999) An introduction to discourse analysis: theory and method. Londres: Routledge.

Gilbert J. K., Boulter C. J., Elmer R. (2000) Positioning models in science education and in design and technology education. En J. K. Gilbert, \& C. J. Boulter (Eds.), Developing models in science education (pp. 3-17). Dordrech: Kluwer Academic Publisher.

Hodson D. (1992) In search of a meaningful relationship: an exploration of some issues relating to integration in science and science education. International Journal of Science Education 14 (5), 541-566.

Jiménez-Aleixandre M. P. (2011) Argumentar y usar pruebas en la clase de ciencias. En M. P. Jiménez-Aleixandre (Eds.), Cuaderno de indagación en el aula y competencia científica (pp. 615). Madrid: Ministerio de Educación. https://sede.educacion.gob.es/publiventa/PdfServlet?pdf=VP15094_19.pdf\&area=E

Jiménez-Aleixandre M. P. (2010) 10 ideas clave. Competencias en argumentación y uso de pruebas. Barcelona: Graó.

Jimenez Aleixandre M. P., Bravo B., Puig B. (2009) ¿Cómo aprende el alumnado a evaluar pruebas?. Aula de Innovación Educativa 186, 10-12.

Jorba J., Sanmartí N. (1996) Enseñar, aprender y evaluar: un proceso de regulación continua: Propuestas didácticas para las áreas de ciencias de la naturaleza y matemáticas. Madrid: CIDE-MEC. 
Kortland K. (1996) An STS Case Study about Students' Decision Making on the Waste Issue. Science Education 80, 673-689.

Kuhn D. (1993) Science as argument: Implications for teaching and learning scientific thinking. Science Education, 77, 391-337.

Lima M., Jiménez-Aleixandre M. P., Mortimer E. F. (2010) Articulation of conceptual knowledge and argumentation practices by high school students in evolution problems. Science \& Education 19, 573-598.

Lundström M., Ekborg M., Ideland M. (2012) To vaccinate or not to vaccinate: how teenagers justified their decision. Cultural Studies of Science Education 7, 193-221. https://doi.org/10.1007/s11422-012-9384-4

Maguregi G., Uskola A., Burgoa, B. (2017) Modelización, argumentación y transferencia de conocimiento sobre el sistema inmunológico a partir de una controversia sobre vacunación en futuros docentes. Enseñanza de las Ciencias 35, 29-50.

Marchán-Carvajal I., Sanmartí N. (2015) Criterios para el diseño de unidades didácticas contextualizadas: aplicación al aprendizaje de un modelo teórico para la estructura atómica. Educación Química 26, 267-274.

Mendonça P. C. C., Justi R. (2013) The relationships between modelling and argumentation from the perspective of the model of modelling diagram. International Journal of Science Education 35, 2407-2434.

Mendonça P. C. C., Justi R. (2014) An instrument for analyzing arguments produced in modeling- based chemistry lessons. Journal of Research in Science Teaching 51, 192-218. https://doi.org/10.1002/tea.21133

Millar R., Osborne J. F. (Eds.). (1998) Beyond 2000: Science Education for the Future. London: King's College London.

Ministerio de Educación, Cultura y Deporte (2014) Real Decreto 126/2014, de 28 de febrero, por el que se establece el curriculo básico de la Educación Primaria. https://www.boe.es/buscar/pdf/2014/BOE-A-2014-2222-consolidado.pdf

Morales P. (2011) El tamaño del efecto (effect size): análisis complementarios al contraste de medias. $\%$ F1oDelEfecto.pdf

Nielsen J. A. (2012) Science in discussions: An analysis of the use of science content in socioscientific discussions. Science Education 96, 428-456.

OECD (2016) PISA 2015 Assessment and Analytical Framework: Science, Reading, Mathematic and Financial Literacy, PISA. Paris: OECD Publishing. http://dx.doi.org/10.1787/9789264255425-en

Oliva J. M. (2019) Distintas acepciones para la idea de modelización en la enseñanza de las ciencias. Enseñanza de las ciencias 37(2), 5-24.

Osborne J. F., Henderson J. B., MacPherson A., Szu E., Wild A., Yao S. (2016) The development and validation of a learning progression for argumentation in science. Journal of Research in Science Teaching 53, 821-846.

Passmore C., Svoboda J. (2011) Exploring opportunities for argumentation in modelling classrooms. International Journal of Science Education 34, 1535-1554. https://doi.org/10.1080/09500693.2011.577842 
Pedrinaci E., Caamaño A., Cañal P., De Pro A. (2013) El desarrollo de la competencia cientifica. 11 ideas clave. Barcelona: Graó.

Puig B. (2010) Argumentación y evaluación de explicaciones causales en ciencias: el caso de la inteligencia. Alambique 63, 11-18.

Puig B., Ageitos N., Jiménez-Aleixandre M. P. (2017) Learning gene expression through modelling and argumentation A case study exploring the connections between the worlds of knowledge. Science \& Education 26, 1193-1222.

Ratcliffe M. (1997) Pupil decision-making about socio-scientific issues within the science curriculum. International Journal of Science Education 19, 167 - 182.

Sadler T. D. (2011) Socio-scientific issues in the classroom. Dordrecht: Springer.

Sadler T. D., Donnelly L. A. (2006) Socioscientific argumentation: The effects of content knowledge and morality. International Journal of Science Education 28, 1463-1488.

Sadler T. D., Fowler S. R. (2006) A threshold model of content knowledge transfer for socioscientific argumentation. Science Education 9, 986-1004. https://doi.org/10.1002/sce.20165

Sadler T. D., Zeidler D. L. (2005) Patterns of informal reasoning in the context of socioscientific decision making. Journal of Research in Science Teaching 42, 112-128. https://doi.org/10.1002/tea.20042

Schwarz C. V., Reiser B. J., Davis E. A., Kenyon L., Achér A., Fortus D., Shwartz Y., Hug B., Krajcik J. (2009) Developing a learning progression for scientific modeling: Making scientific modeling accessible and meaningful for learners. Journal of Research in Science Teaching 46, 632- 654. https://doi.org/10.1002/tea.20311

Simonneaux L. (2008) Argumentation in socio-scientific contexts. En S. Erduran, M. P. Jiménez-Aleixandre (Eds.), Argumentation in science education: perspectives from classroom-based research (pp. 179-199). Dordrecht: Springer.

Solbes, J. (2013). Contribución de las cuestiones sociocientíficas al desarrollo del pensamiento crítico (I): Introducción. Revista Eureka sobre Enseñanza y Divulgación de las Ciencias 10 (1), $1-10$.

Uskola A., Burgoa B., Maguregi, G. (2018) Influencia de la ayuda del profesorado en la construcción del modelo de sistema inmunológico y su aplicación en las tomas de decisión. Revista Eureka sobre Enseñanza y Divulgación de las Ciencias 15, 3604. https://doi.org/ 10.25267/Rev_Eureka_ensen_divulg_cienc.2018.v15.i3.3604.

Uskola A., Maguregi G., Burgoa B. (2017) Toma de decisión sobre la vacunación en contextos de ámbito personal y social en futuros docentes. $X$ Congreso Internacional sobre Investigación en Didáctica de las Ciencias. https://ddd.uab.cat/pub/edlc/edlc_a2017nEXTRA/31.toma_de_decision_sobre_la_v acunacion.pdf

von Aufschnaiter C., Erduran S., Osborne J., Simon S. (2008) Arguing to learn and learning to argue: case studies of how students' argumentation relates to their scientific knowledge. Journal of Research in Science Teaching 45, 101-131. 